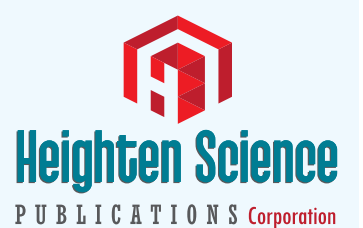

ISSN

2639-9938
*Address for Correspondence: Hatice Demirbas, Gazi University, Faculty of Arts, Department of Psychology Teknikokullar, 06500, Turkey, Tel: +90-312/ 2021345; Fax: +90- 312/ 2131235; E-mail: demirbashatice@hotmail.com

Submitted: 19 December 2016

Approved: 28 January 2017

Published: 30 January 2017

Copyright: @ 2017 Demirbas H. This is an open access article distributed under the Creative Commons Attribution License, which permits unrestricted use, distribution, and reproduction in any medium, provided the original work is properly cited

Keywords: Alcohol use; Childhood Trauma; Neglect; Suicide; Trait anger; Anger expression style

Check for updates

\title{
Predictive Psychological Factors of Problematic Alcohol use in University Students
}

\author{
Hatice Demirbas* \\ PhD, Gazi University, Faculty of Arts, Department of Psychology Teknikokullar, 06500, Ankara, \\ Turkey
}

\section{SUMMARY}

The objective of this study is to determine prevalence of alcohol-substance use among university students, and to investigate the correlation between the childhood abuse, suicide probability and anger expression styles in students who have drinking problems. A survey was carried out among randomly selected students from the Faculty of Education in Baskent University in Turkey. Study sample consists of 399 university students. Childhood Trauma Questionnaire (CTQ), Trait Anger and Anger Expressions Scales (T-Anger-Anger EX), and Suicide Probability Scale (SPS) were used. The CAGE questionnaire was applied to identify the problems of alcohol use. Probable presence of an alcohol use disorder is indicated by a score of $1+$, whereas a score of $2+$ was taken as the cut-off point for assessing presence of clinically significant alcohol use problems. Data were analyzed using with $t$ test and multiple binary logistic regression. Of the whole sample $36.9 \%$ reported that they had ever tried drinking alcohol. The overall prevalence of alcohol use problems according to CAGE $1+$ was $14.4 \%$ and CAGE $2+$ was $7.3 \%$. Sexual abuse and Anger-In were predictors of CAGE $1+$, suicide probability was predictor of CAGE2+. Childhood trauma experiences especially, sexual abuse, suicide probability, trait anger, the anger expressed inside and outside were main factors to identify alcohol use problems. Professionals and parents must pay attention to childhood traumatic experiences, suicide and anger expression styles in youths with alcohol use problems.

\section{INTRODUCTION}

Prevalence of substance use among adolescents and youngsters has increased over time. Alcohol is the substance which is tried the most, repeatedly used, and abused and typically peaks during young adulthood [1-3]. Young people aged 18-25 years residing in Turkey who have consumed alcohol during their lifetime is $13.8 \%-70 \%$ [4-6]. Although majority of the Turkish population is formed by Muslims, the great majority does not live up to the religious principles of Islam, and alcohol use is a socially acceptable phenomenon in Turkey [7]. Looking at the rate of alcohol use problems, poses a serious danger to young people. It is important to know the possible risk factors that can be seen during certain periods of development in order to identify and reduce alcohol use disorder and conduct preventive work. There were multiple risk factors for alcohol abuse problems which increase the size of the risk in the future $[8,9]$. Studies reported that experimentation with alcohol is rather normative in adolescence and that many of them develop a regular drinking pattern.

Risk factors associated with the use of alcohol are experiences of childhood trauma, childhood depression and anxiety disorders. Individual's traumas that they had suffered in childhood affect their whole life. Certain negative life events especially physical/mental abuse in childhood turned out to be the main indicators of addiction and self-destructive behavior [10]. Adverse experiences in childhood leads to different and serious problems in the future such as post-traumatic stress disorder $[11,12]$, 
depression, alcohol and substance use disorders [11,13-16], anxiety and personality disorders [16-18] which are the most common ones[17,19,20].

Childhood abuse is a factor predisposing to the problem of $[14,18]$. Individuals with history of childhood abuse began to drink alcohol at an early age, and have more problems related to alcohol and drug use. The data collected from adults and adolescents indicate that there was a strong relation between use of addictive substances in adulthood and childhood abuse [21]. In the general population, individuals with history of sexual abuse had significantly higher prevalence of alcohol use disorders in a lifetime [22].

Traumatic experiences with young people resulted in an enhancement in alcohol and substance abuse. Also, the risk of suicide attempts was 2-3 times higher in 20\% of young people exposed to sexual abuse [12]. Individuals with high level of childhood trauma reported suicide attempts at an early age and more number of suicide attempts [23]. Anger is also risk factors for alcohol consumption [24]. It is reported that individuals who started using alcohol in an early age had high levels of anger [25].

This study is conducted to determine prevalence of alcohol use among university students in Turkey, and to investigate some predictive psychological factors in alcohol use problems. Experiences of childhood abuse, suicide and anger expressing styles were taken as psychological factors. Finding predictive psychological factors are important to the development of prevention studies.

\section{METHODS}

Study population consists of 399 university students who were randomly selected among 440 students in Baskent University Faculty of Education in Turkey. Females constituted $87.5 \%(n=342)$, and males constituted $13.3 \%(n=53)$ of the sample, and $1.0 \%(\mathrm{n}=4)$ of the students did not state their gender (Table 1). The mean age of the sample was $21.25 \pm 1.97$ between ages 21 to 32 . The age range of first use of alcohol was 10-23.

\section{MEASURES}

The Socio-demographic Form: Socio-demographic characteristics of the students and questions related to alcohol use were asked in this form. Questions related to alcohol use were about the use of alcohol throughout lifetime, last year, last month and last week, and experimented where and with whom.

The Cut down, Annoyed, Guilty and Eye opener (CAGE) Questionnaire: The CAGE questionnaire was developed by Ewing [26] to identify the problems of alcohol use. Validation of the Turkish version of the CAGE questionnaire was done by Gul et al. [27]. The CAGE Questionnaire items are "Have you ever felt you ought to cut down on your drinking?", "Have people annoyed you by criticizing your drinking?", "Have you ever felt bad or guilty about your drinking?" and "Have you ever had a drink first thing in the morning to steady your nerves or get rid of a hangover?" The score on the CAGE scale was established by the addition of the answers of the four questions. A cut-off point of one or more positive answers on the CAGE was shown to be the most valid cutoff point. Probable presence of an alcohol use disorder is indicated by a score of $1+$. A score of two or more positive answers (CAGE2+) is generally used as the cut-off point indicating a serious drinking problem or alcohol dependence. A sensitivity of $75 \%$ to 97\% in detecting alcohol use disorders [27].

\section{Childhood Trauma Questionnaire (CTQ)}

This scale was developed by Bernstein et al. [28], and adapted to the Turkish population by Aslan and Alpaslan [29]. It assesses self-reported experiences of abuse and neglect experienced before the age of 18 years. It consists of 40 items and 


\begin{tabular}{|c|}
\hline Table1: Socio-demographic and background characteristics of the students. \\
\hline Characteristics \\
Gender \\
Female \\
Male \\
\hline Not sated \\
Marital status \\
\hline Single \\
Married \\
\hline Co-habitator \\
\hline Prevalence of alcohol use \\
\hline Last year \\
\hline Last month \\
\hline Last week \\
\hline More than one a month \\
Once a month \\
\hline Fortnightly \\
\hline Once a week or more \\
\hline Experimented where \\
\hline At school \\
\hline At home \\
\hline In student dormitory \\
\hline At bar \\
\hline At outside \\
\hline Other \\
\hline Experimented with whom \\
\hline Alone \\
\hline Friend(s) \\
\hline Close \\
\hline Family \\
\hline
\end{tabular}

3 subscales; Physical Abuse (PA), Emotional Abuse and Neglect (EAN) and Sexual Abuse (SA). Items on the CTQ begin with the phrase "When I was growing up," and are rated on a 5-point Likert-type scale related to frequency of experiences. A high score corresponds to high frequency of experiences of abuse and neglect.

\section{The Trait Anger and the Anger Expressions Scale (T Anger-Anger-EX)}

This scale was developed by Spielberger [30] and adapted to Turkish population by Ozer [31]. It has 34 items and 4 independent subscales designed to evaluate different types of experience and expression of anger. The Trait Anger (T-Anger) is a subscale and measures individual differences in the disposition to experience anger. The other subscales are Anger-In, Anger-Out and Anger-Control (Anger-EX). The Anger-in (AEX In) measures the frequency with which anger feelings are held or suppressed, the Anger-out (AEX-Out) measures the frequency with which anger is expressed toward other people or objects in the environment and the Anger Control (AEX-Con) measures an individual's capacity to control the expression. Higher score in the T Anger-Anger EX reflects a higher level of anger.

The Suicide Probability Scale (SPS). This scale was developed by Cull and Gill [32] and adapted to the Turkish population by Tugcu [33]. It has 36 items and four subscales; hopelessness, suicidal ideation, negative self-assessment and hostility. Higher score in the SPS reflects a higher the probability of suicide.

\section{PROCEDURE}

The present study was approved by the Baskent University. Psychological assessment instruments were given to students in different order. Instruments were distributed to the participants in sealed envelopes to ensure confidence by lecturers while they were in attendance of a required course. Informed consent was obtained 
Table 2: Alcohol use prevalence among gender.

\begin{tabular}{|c|c|c|c|c|c|c|}
\hline \multirow{2}{*}{ Alcohol use prevalence } & \multicolumn{2}{|c|}{ Female } & \multicolumn{2}{|c|}{ Male } & \multirow[b]{2}{*}{$x^{2}$} & \multirow[b]{2}{*}{$\mathbf{p}$} \\
\hline & $\mathbf{n}$ & $\%$ & $\mathbf{n}$ & $\%$ & & \\
\hline In the last year & 118 & 34.5 & 27 & 50.9 & 5.333 & $0.021^{\star}$ \\
\hline In the last month & 78 & 22.8 & 20 & 37.7 & 5.482 & $0.019 *$ \\
\hline In the last week & 29 & 8.5 & 16 & 30.2 & 21.424 & $0.000 * *$ \\
\hline
\end{tabular}

from the participants after giving information about the study procedure. Filling the instruments took between 30 and 40 minutes.

\section{STATISTICAL ANALYSIS}

Prevalence of last alcohol use according to gender was tested by the Student t test. Univariate analysis was carried out on the relationships between psychological tests and alcohol use. Alcohol use was taken as either the presence or the absence of alcohol use problem according to the CAGE1+ and CAGE2+ score. Next, the relationships which were found to be significant in the univariate analysis were reassessed using forward stepwise binary multiple logistic regression models. CAGE1+ and CAGE2+ were taken as the dependent variables in the logistic regression analysis. SPSS 20.0 statistical software program were used for the statistical analyses.

\section{RESULTS}

Of the whole student sample 39.6\% $(n=158)$ reported that they had ever tried drinking alcohol. Use of alcohol rate was 36.8\% in the last year, $24.6 \%$ in the last month and $11.3 \%$ in the last week. Prevalence of alcohol use according to gender was given in table 2. Consumption of alcohol use of male and female students in the last year, in the last month and in the last week was a statistically significant difference. Greater percentage of the male students used alcohol compared with the female students in the last year, in the last month and in the last week. Students reported that they had experimented alcohol firstly with their friends (30.1\%) and their families (9.8\%). They experimented alcohol at home $(29.6 \%)$ and in bar $(10.5 \%)$. In terms of past year drinking frequency, $20.8 \%$ of the students answered that they had been drinking once a month or less frequently and $10.8 \%$ had been drinking more than once a month.

The overall prevalence of problematic alcohol use was $14.8 \%(n=59)$ according to CAGE1+ and 7.5\% (n=30) according to CAGE2+. According to CAGE $1+, 14.4 \%$ of the students (12\% female and $30.2 \%$ male), according to CAGE $2+, 7.3 \%$ of the students (6.4\% female and $13.2 \%$ male) had problematic alcohol use. Male students used alcohol more frequently $\left(\chi^{2}=12.310, p=0,000\right)$ and more problematically compared with the females according to CAGE $1+$.

Independent sample t-test was conducted to determine the difference between the means of the psychological tests according to CAGE1+ and CAGE2+. Results indicated that there were statistically significant differences between means of total childhood abuse, sexual abuse, suicide probability, T-Anger, Anger-In and Anger-Out scores and CAGE1+. Also there were statistically significant differences between the suicide probability, T-Anger, Anger In and CAGE2+ (Table 3).

The statistically significant relationships were tested by binary multiple logistic regression models. CAGE1+ and CAGE2+ were taken as the dependent variables in the logistic regression analysis. Results showed that anger-in (OR=1.116, 95\%CI: 1.041 1.197) and sexual abuse (OR=1.135, 95\%CI: 1.010-1.275) were significantly related with alcohol use problems according to the CAGE $1+$. Suicide probability $(\mathrm{OR}=1.035$, 95\%CI: 1.016-1.056) was significantly related with alcohol use problems according to CAGE $2+$. 


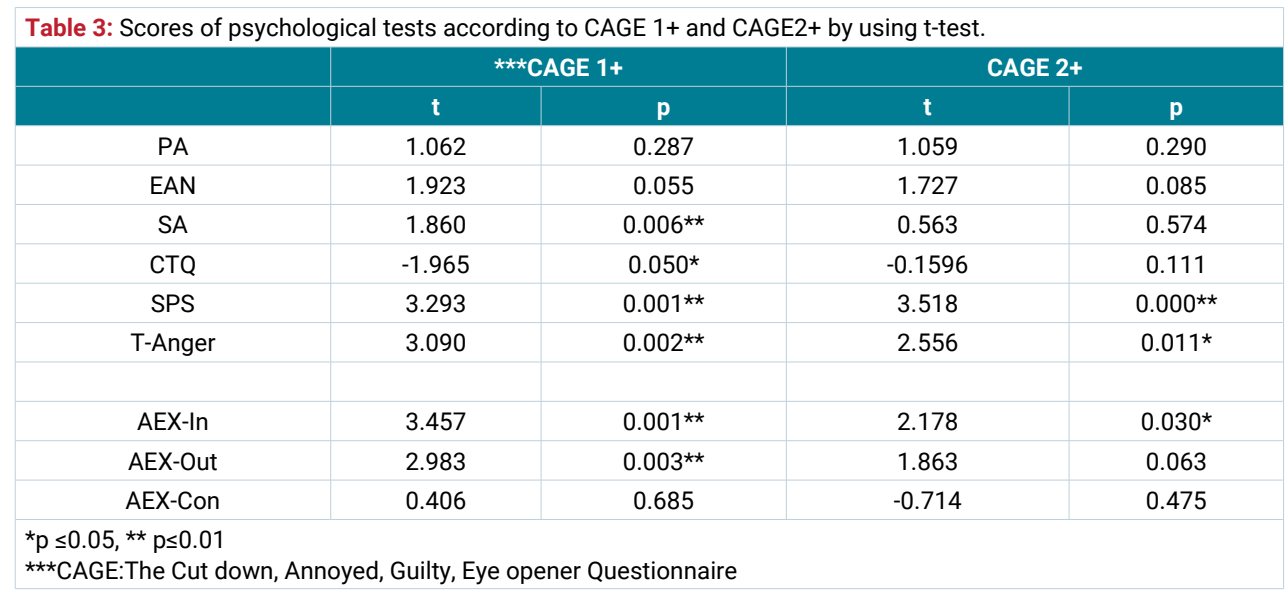

\section{DISCUSSION}

In this study, it was sought to investigate the prevalence of alcohol use among university students and to investigate whether the alcohol use problem is related to childhood abuse, the possibility of suicide and anger expressing styles.

The prevalence of alcohol use among university students was 39.6\%. This finding is consistent with prevalence rates in other studies. In studies conducted in European countries, the prevalence of alcohol use at least once in life ranged from $42 \%$ to $95 \%$ [34-36], while studies in Turkey ranged from $35.6 \%$ to $78.7 \%$ [2,7,37-40]. In this study, use of alcohol rate was $36.8 \%$ in the last year, $24.6 \%$ in the last month and $11.3 \%$ in the last week. This rate was lower than other studies. The rate of alcohol use was reported $51.0 \%-72.3 \%$ for the last year, for the last month $43.8 \%-60.3 \%[6,40,41]$. A low prevalence rate may be related to the majority of the sample being formed by females. Study results showed that rate of problematic alcohol use in male students was higher than female students according to CAGE1+ $(14.4 \%)$ and CAGE2+ (7.4\%). Consistent to this finding, there were another studies reported that high rate of problematic alcohol use in university students [2,7].

In this study, experiences of childhood abuse were found to be a risk factor for use of alcohol in later life. In this risk factor, sexual abuse was a crucial variable. There were another studies supporting the findings by $[14,16]$ and not supporting to findings by [11]. Although Marx and Sloan [11] evaluated the history of abuse in their study, score of abuse was taken to analyses in this study. Prevalence of childhood neglect and abuse was high among people who use substance [14]. Ballon, Courbasson and Smith [42] stated that one-half of the female youth substance abusers reported having been sexually abused (50.0\%) and one-half of the female youths had a history of physical abuse (50.5\%). Of those who exposed a history of abuse, more females $(64.7 \%)$ than males $(37.9 \%)$ reported using substances to cope with the trauma. Specific associations between the outcome measures and substance use variables were found for youths in both sexes [43]. Childhood physical abuse was related with alcohol use and, social and psychiatric problems $[43,44]$. The study results reported that there is a significant relationship between severity of childhood abuse and posttraumatic stress disorder (PTSD) for alcohol using male patients who admit treatment [45] as well as high percentage of substance abuse with PTSD and childhood physical and/or sexual abuse in female [46].

The current results were in line with research indicating that emotional abuse score was high in substance use university students $[13,16]$. Especially rate of emotional abuse, physical abuse [29] and sexual abuse [16] were high in females. Emotional abuse is different from other types of traumas as the structure is more complex and is covered. After physiological signs of physical and sexual abuse, emotional abuse 
continues its presence and effects [47]. Results revealed that sexual abuse increases the likelihood of problematic alcohol use. Childhood abuse hampers the development of sensation regulation skills with experiences of neglect in early development period [48]. Victims used substance to cope with intense emotions as an inappropriate mechanism [44]. Youngsters prefer "chemical escape" to escape from negative effects of abuse experiences and may be use substance for self-medication to cope with stress [11].

Of individuals who were exposed to traumatic experiences in childhood, experience more emotional and behavioral problems and self-harm and suicide attempts become possible in later life [8]. Namely, childhood trauma contributes to the initiation of selfdestructive behaviour. Histories of childhood sexual and physical abuse were highly significant predictors of self-cutting and suicide attempts [49]. The high probability for suicide was related with high risk for alcohol use in this study. The young people with alcohol use problems are more likely to commit suicide than young non-issue. Consistent with results of this study, positive correlations between adverse childhood experiences and suicide attempts have been reported in addicted patients with childhood abuse history [12,15,50]. Sexual abuse had direct effects on self-injurious behaviour and substance use among both genders, when controlling for age, family structure, parental education, anger, and depressed mood [52]. As the childhood experience scores increase the suicide attempts increase 60\% [8]. In one study, rate of physical abuse, emotional abuse and neglect and, self-injury were higher for alcohol addicted patients than non-addicted patients. Of patients with suicide attempt history $45.5 \%$, reported childhood physical abuse $31.8 \%$ reported emotional abuse, $59.1 \%$ neglect and $56.8 \%$ self-cutting [14]. High level of T-Anger was predictor of suicidal behavior in university students [53]. Therefore, history of childhood trauma, high suicide probability, high level of trait anger, anger expression in and anger expression outside are related variables for alcohol use problems according to the findings of this study. Especially trait anger and the anger that is experienced but held in or suppressed have more predictive significance for alcohol use than other anger expression styles. The presence of high probability for suicide was related to a high level of T-Anger, Anger-out and Anger-in alcohol inpatients [54]. Also, facets of anger are relevant predictors of suicide attempts with a history of childhood sexual victimization [55].

Anger level is effective in adolescent substance use. There was a relationship between the use of tobacco, alcohol, cannabis use one year to the next and anger level of adolescents with noted above [56]. University students with sexual abuse experiences in childhood have reported high level of anger [57,58]. Experiences of anger, aggression, and irritability are claimed with the traumatic experiences. University students with high level of anger have a probability to start ahead of the high alcohol consumption [59]. The students with alcohol use problems are high levels of trait anger, and the anger expressed by hitting the outside or said that they suppress either. Extreme level of the trait anger is a potential mediator in many self-damaging behaviors [60]. In this way, anger turns into self-damaging behavior as suicide thought, plan and attempt [53].

The study has some limitations. First, it was cross-sectional study. The sample was composed of a majority of female university students. The other limitations were that the reliance on self-report measures where recall biases and inaccuracy of reported behaviors cannot be ruled out.

As a result, high level of childhood abuse experiences especially being exposed to sexual abuse, suicide probability, trait anger, anger expression styles; the anger that is experienced but held in or suppressed and the anger expressed toward other people or objects in the environment were associated with alcohol use problems. As a conclusion, 
professionals and parents should be careful to childhood abuse experiences, suicide probability, trait anger and anger expression styles in young people with problematic alcohol use. Also, clinicians should evaluate and assess these factors in youths with problematic alcohol use in order to provide better intervention strategies.

\section{REFERENCES}

1. Koposov RA, Ruchkin VV, Eisemann M, Sidorov PI. Alcohol use in adolescents from Northern Russia: the role of the social context. Alcohol \& Alcoholism. 2002; 37: 297-303. Ref.: https://goo.gl/x2sx7h

2. Demirbas $H$. Substance and alcohol use in young adulthood in Turkey as indicated by CAGE questionnaire and drinking frequency. Arch Neuropsychiatr. 2015; 52: 29-35. Ref.: https://goo.gl/EvdWSD

3. Palmer RHC, Young SE, Hopfer CJ, Corley RP, Stallings MC, et al. Developmental epidemiology of drug use and abuse in adolescence and young adulthood: evidence of generalized risk. Drug Alcohol Depend. 2009; 102: 78-87. Ref.: https://goo.gl/hZYqdO

4. Akvardar $Y$, Demiral $Y$, Ergor $G$, Ergor A. Substance use among medical students and physicians in a medical school in Turkey. Soc Psychiatry Psychiatr Epidemiol. 2004; 39: 502-506. Ref. https://goo.gl/NJ57zu

5. Altındag A, Yanik M, Yengil E, Karazeybek AH. Substance use among university students in Sanliurfa. Journal of Dependence. 2005; 6: 60-64.

6. Özgur-İlhan I, Yıldırım F, Demirbas H, Doğan YB. Substance use prevalence and sociodemographic correlates of substance use in a university student sample in Turkey. Int J Public Health. 2009; 54 40-44. Ref.: https://goo.gl/RbxhkO

7. Özgur-IIlhan I, Yıldırım F, Demirbas H, Doğan YB. Alcohol use prevalence and sociodemographic correlates of alcohol use in a university student sample in Turkey. Soc Psychiatry Psychiatr Epidemiol. 2008; 43: 575-583. Ref.: https://goo.gl/814y4M

8. Dube SR, Anda AF, Felitti VJ, Chapman DP, Williamson DF. Childhood abuse, household dysfunction and the risk of attempted suicide throughout the life span. Journal of the American Medical Association. 2010; 286: 3089-3096. Ref.: https://goo.gl/BLB2gz

9. Öztürk OM, Uluşahin A. Ruh Sağıı̆ı ve Bozuklukları. Yenilenmiş 11. Baskı. Ankara:Tuna Matbaacılık San. ve Tic. A.Ş. 2008; 496-504.

10. Osvath P, Vörös V, Fekete S. Life Events and Psychopathology in a Group of Suicide Attempters. Psychopathology. 2004; 37: 36-40. Ref.: https://goo.gl/YHdJKG

11. Marx BP, Sloan DM. The effects of trauma history, gender, and race on alcohol use and posttraumatic stress symptoms in a college student sample. Addictive Behaviors. 2003; 28: 1631-1647. Ref.: https://goo.gl/jZPYmp

12. Wilcox HC, Arria AM, Calderia KM, Vincent KB, Pinchevsky GM, et al. Prevalence and predictors of persistent suicide ideation, plans, and attempts during college. Journal of Affective Disorders. 2010; 127, 287-294. Ref.: https://goo.gl/bdW6kV

13. Bostancı N, Albayrak B, Bakoğlu İ, Çoban Ş. Üniversite öğrencilerinde çocukluk çağı travmalarının depresif belirtileri üzerine etkisi. Yeni Sempozyum. 2006; 44: 100-106.

14. Evren C, Kural S, Çakmak D. Clinical correlates of childhood abuse and neglect in substance dependents. Addictive Behaviors, 2006; 31: 475-485. Ref.: https://goo.gl/PVjiMV

15. Mırsal H, Pektaş Ö, Kalyoncu A, Tan D, Bilge Ö, et al. İntihar girişiminde bulunan alkol bağımlılarında çocukluk çağı olumsuz yaşantıları. 40. Ulusal Psikiyatri Kongresi. Kongre Bildirileri Özet Kitabı, İzmir. 2004.

16. Saleptsi E, Bichescu D, Rockstroh B, Neuner F, Schauer M, et al. Negative and positive childhood experiences across developmental periods in psychiatric patients with different diagnosis-an explorative study. BMC Psychiatry, 2004; 4: 1-14. Ref.: https://goo.gl/BLeXK4

17. Allen B, Lauterbach D. Personality characteristics of adult survivors of childhood trauma. Journal of Traumatic Stress. 2007; 20: 587-595. Ref.: https://goo.gl/TNFjSj

18. Kural S, Evren C, Çakmak D. Personality disorder comorbidity among substance dependents and its relationship with other axis I disorders and childhood abuse and neglect history. Journal of Dependence. 2005; 6: 9-18.

19. Breslau N, Peterson EL, Schultz LR. A second look at prior trauma and the posttraumatic stres disorder effects of subsequent trauma. Arch Gen Psychiatry. 2008; 65: 431-437. Ref. https://goo.gl/zVtgXn

20. Brodsky BS, Oquendo M, Ellis SP, Haas GL, Malone KM, et al. The relationship of childhood abuse to impulsivity and suicidal behavior in adults with major depression. American Journal of Psychiatry, 2001; 158: 1871-1877. Ref.: https://goo.gl/QIwbnN 
21. Brems $C$, Johnson ME, Neal D, Freeman M. Childhood abuse history and substance use among men and women receiving detoxification services. American J Drug Alcohol Abuse. 2004; 30: 799-821. Ref.: https://goo.gl/Jy6IVR

22. Molnar BE, Buka SL, Kessler RC. Child sexual abuse and subsequent psychopathology: results from the national comorbidity survey. American Journal of Public Health, 2001; 91: 753-760. Ref.: https://goo.gl/ILROnN

23. Roy A. Relationship of childhood trauma to age of first suicide attempt and number of attempts in substance dependent patients. Acta Psychiatrica Scandanivica. 2004; 109: 121-125. Ref.: https://goo.gl/Q0e9L1

24. Milgram GG. Adolescents, alcohol and aggression. Journal of Studies on Alcohol Supplement, 1993 11: 53-61. Ref.: https://goo.gl/kiimzi

25. Weiner MD, Pentz MA, Turner GE, Dwyer JH. From early to late adolescence. Alcohol use and anger relationships. Journal of Adolescence Health. 2001; 28: 450-457. Ref.: https://goo.gl/uxdelC

26. Ewing JA. Detecting alcoholism. The CAGE Questionnaire. JAMA. 1984; 252: 1905-1907. Ref. https://goo.gl/uBOKOD

27. Gul S, Akvardar Y, Tas G, Tuncel P. The Diagnostic Validity of Screening Tests and Laboratory Markers in Alcohol Use Disorders. Turk Psikiyatri Dergisi. 2004; 16: 3-12. Ref.: https://goo.gl/TI7Sq6

28. Bernstein DP, Fink L, Handelsman L, Foote J, Lovejoy M, et al. Initial reliability and validity of a new retrospective measure of child abuse and neglect. American Journal of Psychiatry. 1994; 151: 11321136. Ref.: https://goo.gl/e1D4db

29. Aslan $\mathrm{SH}$, Alparslan ZN. Initial validity and reliability of the Turkish version of the childhood trauma questionnaire. Annals of Medical Sciences. 2000; 9: 113-119.

30. Spielberger CD. Manual for The State-Trait Anger Expression Scale (STAXI). Odessa, FL:Psychologica Assessment Resources. 1988.

31. Özer AK. Pilot study of Trait-Anger and Anger Expression Styles Inventories. Turk Psikoloji Dergisi. 1994; 9: 26-35.

32. Cull JG, Gill WS. Suicide Probability Scale Manual. Los Angeles, Western Psychological Services. 1990.

33. Tugcu H. Suicide probability in normal and depressive people. Unpublished doctora thesis, Hacettepe University, Ankara. 1996.

34. Dantzer C, Wardle J, Fuller R, Pampalone SZ, Stepto A. International study of heavy drinking students. J Am Coll Health. 2006; 5: 83-89. Ref.: https://goo.gl/DdgLWu

35. Isralowitz RE, Peleg A. Israeli college student alcohol use: the association of background characteristics and regular drinking patterns. Drug and Alcohol Dependence. 1996; 42: 147-153. Ref.: https://goo.gl/1OYOsF

36. Passos SRI, Americano do Brasil PEA, Porges dos Santos MA, Costa de Aquino MT. Prevalence of psychoactive drug use among medical students in Rio de Janerio. Soc Psychiatry Psychiatr Epidemiol. 2006; 41: 989-996. Ref.: https://goo.gl/vhdCTH

37. Ögel K, Tamar D, Özmen E, Evren C, Çakmak D. Prevalence of alcohol use in Istanbul. Journal of Psychiatry, Psychology and Psychopharmacology. 2003; 11: 123-127. Ref.: https://goo.gl/ZjEu6J

38. Akfert SK, Çakıcı E, Çakıcı M. Cigarette and alcohol use among university students and its relationship with family problems. Anatolian Journal of Psychiatry. 2009; 10: 40-47.

39. Babacan-Gümüş A. Cigarette and Alcohol Use Among University Students: An Evaluation in Terms of Depressive Symptoms and Hopelessness. Journal of Dependence. 2015; 16: 9-17. Ref. https://goo.gl/f9b9c6

40. Avcı E, İlhan MN, Civil EF, Özdemirkan T, Bumin MA. Prevalence of the tobacco alcohol and products use of a faculty of medicine students and risk factors. Journal of Dependence. 2014; 15: 48-55. Ref.: https://goo.gl/fw52oU

41. Hunter SB, Miles JNV, Pedersen E R, Ewing BA, D'Amico EJ. Temporal associations between substance use and delinquency among youth with a first time offense. Addictive Behaviors. 2014 39: 1081-1086. Ref.: https://goo.gl/gUhqjL

42. Ballon BC, Courbasson CM, Smith PD. Physical and sexual abuse issues among youths with substance use problems. Canadian Journal of Psychiatry. 2001; 46: 617-21. Ref.: https://goo.gl/bZnyc8

43. Rodriquez-Srednicki O. Childhood sexual abuse, dissociation, and adult self-destructive behaviour. Journal of Child Sexual Abuse. 2002; 10: 75-89. Ref.: https://goo.gl/fNuj7y

44. Zlotnick C, Johnson DM, Stout RL, Zywiak WH, Johnson JE, et al. Childhood abuse and intake 
severity in alcohol disorder patients. Journal of Traumatic Stress. 2006; 19: 949-959. Ref.: https://goo.gl/KgYN2U

45. Langeland W, Draijer N, van den Brink W. Psychiatric comorbidity in treatment-seeking alcoholics: the role of childhood trauma and perceived parental dysfunction. Alcoholism: Clinical and Experimental Research. 2004; 28: 441-447. Ref.: https://goo.gl/AHHUvA

46. Najavits LM, Weiss RJ, Shaw SR. The link between substance abuse and posttraumatic stres disorder in women. A research review. American Journal of Addiction. 1997; 6: 273-2283. Ref.: https://goo.gl/NadZuD

47. Aydın 0 , İşmen AE. Investigation of childhood abuse experiences between $18-25$ years old males. M.Ü. Atatürk Eğitim Fakültesi Eğitim Bilimleri Dergisi. 2003; 18: 7-20.

48. van der Kolk BA, Hostetler A, Herron N, Fisler RE. Trauma and the development of borderline personality disorder. Psychiatric Clinics of North America. 1994; 17: 715-730. Ref.: https://goo.gl/GwkKuO

49. van der Kolk BA, Perry JC, Herman JL. Childhood origins of self-destructive behavior. American Journal of Psychiatry. 1991; 148: 1665-1671. Ref.: https://goo.gl/oMFkca

50. Brown GR, Anderson B. Psychiatric morbidity in adult inpatients with childhood histories of sexual and physical abuse. American Journal of Psychiatry. 1991; 148: 55-61. Ref.: https://goo.gl/GWkHNk

51. Krarup G, Nielsen B, Rask P, Petersen P. Childhood experiences and repeated suicidal behavior. Acta Psychiatrica Scandinavica. 1991; 83: 16-19. Ref.: https://goo.gl/Sg4nju

52. Asgeirsdottir BB, Sigfusdottir ID, Gudjonsson GH, Sigurdsson JF. Associations between sexual abuse and family conflict/violence, self-injurious behavior, and substance use: The mediating role of depressed mood and anger. Child Abuse \& Neglect. 2011; 35: 210-219. Ref.: https://goo.gl/cOJrdH

53. Demirbas $\mathrm{H}$, Gursel C. Examination of anger and suicidal behaviors among university students. Procedia-Social and Behavioral Sciences. 2012; 47: 2093-2098. Ref.: https://goo.gl/KFmA3z

54. Demirbas H, Ozgur-Ilhan I, Dogan YB. Assessment of the mode of anger expression in alcohol dependent male inpatients. Alcohol and Alcoholism. 2011; 46: 542-546. Ref. https://goo.gl/w2WPiq

55. Sadeh N, McNiel DE. Facets of anger, childhood sexual victimization, and gender as predictors of suicide attempts by psychiatric patients after hospital discharge. Journal of Abnormal Psychology, 2013; 122: 879-90. Ref.: https://goo.gl/qPdQfC

56. Nichols TR, Mahadeo M, Bryant K, Botvin GJ. Examining anger as a predictor of drug use among multiethnic middle school students. Journal of School Health. 2008; 78: 480-486. Ref.: https://goo.gl/XN7TLV

57. Chen J, Dunne MP, Han P. Child sexual abuse in China: a study of adolescents in four provinces. Child Abuse and Neglect. 2004; 28: 1171-1186. Ref.: https://goo.gl/Y2QqiO

58. Sun YP, Zhang B, Dong ZJ, Yi MJ, Sun DF, Shi SS. Psychiatric state of college students with a history of childhood sexual abuse. World Journal of Pediatry. 2008; 4: 289-294. Ref. https://goo.gl/g9pZPe

59. Armeli S, Todd M, Conner TS, Tennen H. Drinking to cope with negative moods and the immediacy of drinking within the weekly cycle among college students. Journal of Studies Alcohol and Drugs. 2008; 69: 313-322. Ref.: https://goo.gl/u2II98

60. Olatunji BO, Lohr JM. Nonspecific factors and the efficacy of psychosocial treatments for anger. SRMHP. 2005; 3: 1-26. Ref.: https://goo.gl/z90j30 